\title{
Analisis Pemilihan Supplier Yang Tepat Untuk Produk Gigi Palsu (Studi Kasus Di CV. Brother Dent)
}

\author{
Agus Syamsudin $^{1^{*}}$, Ellysa Nursanti $^{2}$, Emmalia Adriantantri $^{3}$ \\ ${ }^{1}$ Mahasiswa Progam Studi Teknik Industri, Fakultas Teknologi Industri, Institut Teknologi Nasional Malang \\ ${ }^{2}$ Progam Studi Teknik Industri, Pascasarjana, Institut Teknologi Nasional Malang \\ ${ }^{3}$ Progam Studi Teknik Industri, Fakultas Teknologi Industri, Institut Teknologi Nasional Malang \\ *Email: agussyamsudin117@yahoo.com
}

\begin{abstract}
Abstrak
Dalam konsep rantai pasok, supplier merupakan salah satu bagian rantai pasok yang sangat penting dan berpengaruh terhadap eksistensi suatu perusahaan. Untuk mendapatkan supplier yang tepat, perusahaan perlu melakukan pemilihan supplier dikarena supplier memegang peranan sangat penting untuk memperlancar proses produksi dalam suatu industri manufaktur. Bahan baku yang dipilih harus sesuai kualitas standar dari perusahaan. Oleh karena itu CV. Brother Dent memerlukan supplier yang tepat untuk memenuhi kebutuhan bahan baku tersebut. Saat ini masih banyak terjadi keterlambatan bahan baku dan juga kualitas bahan baku yang tidak sesuai dengan standart sehingga pemilihan supplier harus diperhatikan dengan benar. Penelitian ini bertujuan untuk mengetahui supplier mana yang memiliki performa terbaik dengan menggunakan metode AHP sebagai dasar pemilihan kriteria dan sub kriteria supplier dan Alat yang dipakai dalam penelitian ini adalah Aplikasi Expert Choice yang digunakan untuk membantu pengambilan keputusan dalam pemilihan supplier. Pengolahan data yang dilakukan menggunakan metode Analytical Hierarchy Process (AHP) dan tahap-tahap yang dilakukan dalam metode AHP yaitu mendefinisikan struktur hirarki permasalahan, menghitung bobot kriteria pada setiap tingkat hirarki, menghitung konsistensi pembobotan dan menampilkan urutan prioritas alternatif. Aplikasi expert choice digunakan untuk memilih supplier mana yang tepat yang dipilih untuk menyuplai bahan baku metal porcelin pada CV. Brother Dent. Hasil kuesioner 1 menunjukkan bahwa kriteria yang baik dalam memilih supplier bahan baku metal porcelin adalah Kualitas, Harga, Pengiriman, Pelayanan, Fleksibilitas. Pengolahan data pada Kuesioner 2 menggunakan metode AHP diketahui kriteria pengiriman menjadi prioritas utama yaitu dengan bobot 0,39 . Hasil penilaian dari hasil wawancara untuk menentukan supplier terbaik yang sudah diolah menggunakan aplikasi Expert Choice menunjukkan supplier Royal Dent sebagai prioritas pertama dengan bobot 0,414.
\end{abstract}

Kata Kunci : Analytical Hierarchy Process (AHP), Expert Choice, Pemilihan Supplier, Pengambilan Keputusan.

\section{Pendahuluan}

Dalam konsep rantai pasok, supplier merupakan salah satu bagian rantai pasok yang sangat penting dan berpengaruh terhadap eksistensi suatu perusahaan [1]. Untuk menentukan mitra bisnis inilah diperlukan sebuah konsep Supply Chain Management (SCM) agar tidak salah memilih mitra bisnis [2]. Untuk mendapatkan supplier yang tepat, perusahaan perlu melakukan pemilihan supplier untuk memperlancar proses produksi dalam suatu industri manufaktur. Bahan baku yang dipilih harus sesuai kualitas standar dari perusahaan. Oleh karena itu CV. Brother Dent memerlukan supplier yang tepat untuk memenuhi kebutuhan bahan baku tersebut. Berdasarkan informasi yang didapat, perusahan ini telah bekerja sama dengan tiga supplier bahan baku metal porcelin untuk mendukung proses produksinya, yaitu Royal Dent, Tatia Dental, Densplay. Namun pada kenyataannya proses produksi sering terhambat akibat keterlambatan pengiriman bahan baku metal porcelin dan kualitas bahan baku yang tidak konsisten. Masalah yang dialami oleh perusahaan adalah sulitnya menentukan supplier mana yang memiliki performansi yang terbaik dari segi waktu, kualitas dan kuantitas sehingga perusahaan 
bisa memprioritaskan supplier tersebut dalam memenuhi bahan baku penunjang yang dibutuhkan untuk memperlancar proses produksi [3]. Dengan melakukan perhitungan dengan AHP (Analytical Hierarchy Process) bisa lebih cepat dibandingkan perhitungan secara manual sehingga bisa lebih efisien dan tingkat keakuratan data sudah mendekati sempurna [4]. Tujuan dari penelitian ini yaitu menentukan kriteria yang baik dalam pemilihan supplier bahan baku metal porcelin dan menentukan supplier terbaik di CV. Brother Dent. Teknik yang dibahas dalam situasi pengambilan keputusan supplier bahan baku ini adalah teknik Analytical Hierarchy Process (AHP), teknik ini dikembangkan oleh Thomas L Saaty tahun 1970. Untuk itu penerapan Sistem Pendukung keputusan dengan menggunakan metode Analytical Hierarchy Process (AHP) dengan Aplikasi Expert Choice sangat penting sebagai upaya untuk pemilihan supplier dengan performansi terbaik [5].

\section{Metode Penelitian}

Metode penelitian yang dibuat akan membuat peneliti lebih mudah dalam melakukan penelitian. Dimana metode tersebut akan dipraktekkan secara langsung maupun dalam sebuah teori. Hal ini agar hasil penelitian sesuai dengan apa yang diharapkan.

\section{Pengumpulan Data}

Dalam pengumpulan data digunakan beberapa metode agar berhubungan dengan masalah yang di teliti. Adapun metode yang digunakan adalah sebagai berikut :

Wawancara yang dilakukan di CV. Brother Dent adalah dengan cara bertanya terhadap pihak-pihak yang bersangkutan di mana pada kasus ini bertanya pada bagian pemesanan bahan baku untuk memperoleh supplier terbaik. Wawancara dilakukan untuk memilih supplier mana yang memiliki nilai atau performa terbaik yang di berikan pada bagian pemesanan barang dengan memberikan nilai interval penilaian yaitu (1-10). Observasi Melakukan pengamatan secara langsung di CV. Brother Dent. Kuesioner yang dibuat terdiri dari 2 jenis, yaitu Kuesioner Pemilihan Kriteria supplier, Kuesioner Perbandingan berpasangan Kriteria, dan Kuesioner Perbandingan berpasangan Sub Kriteria. Penentuan responden Untuk kuesioner pemilihan kriteria dan sub kriteria, responden berjumlah 10 karyawan yang bekerja di CV. Brother Dent. Penyusunan dan penyebaran kuesioner I disebarkan untuk memperoleh kriteria dan sub kriteria yang digunakan dalam pengambilan keputusan untuk pemilihan supplier di CV. Brother Dent. Penyusunan dan penyebaran kuesioner II dilakukan setelah terbentuk hirarki. Kuesioner II berisi penilaian tingkat kepentingan (bobot) untuk kriteria dan Sub kriteria dengan menggunakan Skala 1-9 Saaty. Sub kriteria yang digunakan dalam penghitungan Bobot kriteria dapat dilihat pada Tabel 1berikut.

Tabel 1. Kriteria, Sub Kriteria Dan Literatur Yang Digunakan Dalam AHP [6] , [7]

\begin{tabular}{|c|c|c|}
\hline Kualitas & Sub Kriteria & Literatur Yang Diambil \\
\hline \multirow{3}{*}{ kualitas } & Penyediaan Barang Tanpa Cacat & Surjasa, Dadang, dkk (2006) \\
\cline { 2 - 3 } & Kesesuaian Barang Dengan Spesifikasi Yang sudah Ditetapkan & Surjasa, Dadang, dkk (2006) \\
\cline { 2 - 3 } & Kemampuan Memberikan Kualitas Yang Konsisten & Surjasa, Dadang, dkk (2006) \\
\hline Harga & Harga Sesuai Dengan Yang Telah Disepakati & Yanuar Angga Prayoga, (2016) \\
\hline \multirow{3}{*}{ Pengiriman } & Ketepatan Waktu Pengiriman Sesuai Yang Telah Disepakati & Surjasa, Dadang, dkk (2006) \\
\cline { 2 - 3 } & Kesesuaian Jumlah Bahan Baku Dikirim Dengan Dipesan & Yanuar Angga Prayoga, (2016) \\
\cline { 2 - 3 } & Kemampuan Dalam Hal Penanganan Sistem Transportasi & Surjasa, Dadang, dkk (2006) \\
\hline \multirow{3}{*}{ Pelayanan } & Respon Dalam Menerima Keluhan Terhadap Supplier & Yanuar Angga Prayoga, (2016) \\
\cline { 2 - 3 } & Kemudahan Supplier Untuk Dihubungi & Surjasa, Dadang, dkk (2006) \\
\cline { 2 - 3 } & Kecepatan Dalam Hal Menanggapi Permintaan & Surjasa, Dadang, dkk (2006) \\
\hline \multirow{3}{*}{ Fleksibilitas } & Yanuar Angga Prayoga, (2016) \\
\cline { 2 - 3 } & Kemampuan Supplier Dapat Memenuhi Kebutuhan Pemesanan & Yanuar Angga Prayoga, (2016) \\
\hline
\end{tabular}

\section{Pengolahan Data}

Penyusunan Hirarki Hasil yang diperoleh dari kuesioner I kemudian digunakan sebagai dasar untuk menyusun hirarki yang disusun terdiri dari beberapa level. Hirarki ini disusun untuk menjelaskan masalah secara terstruktur dan mudah dipahami. Pembobotan Kriteria dan Sub Kriteria dengan metode AHP Pada tahap ini akan dihitung bobot untuk masing - masing kriteria dan sub kriteria yang ada pada 
struktur hirarki. Pengujian Konsistensi Pengujian konsistensi dilakukan untuk menguji penilaian perbandingan antar kriteria dan sub kriteria konsisten atau tidak. Jika hasil yang diperoleh menunjukkan tidak konsisten maka dapat dilakukan perhitungan revisi atau bahkan penilaian ulang oleh responden. Penentuan supplier terbaik didapat dari wawancara diolah dengan menggunakan aplikasi expert choice untuk mengetahui supplier mana yang memiliki performa terbaik yang akan dipilih untuk menyuplai bahan baku di CV. Brother Dent. Analisa Data Tahap analisa data adalah untuk melihat dari hasil pengolahan data yaitu supplier yang perlu Diprioritaskan sesuai kebijakan perusahaan, sehingga bisa di jadikan acuan untuk pilihan terbaik bagi Perusahaan.

\section{Hasil Dan Pembahasan}

\section{Pengolahan data menggunakan metode AHP}

Pada tahapan ini, Responden memberikan penilaian kepada tiap supplier bahan baku Metal Porcelin dengan membagikan kuisioner untuk setiap kriteria dan sub kriteria [8]. Sub kriteria yang digunakan adalah hasil performansi yang sudah diperlihatkan oleh supplier-supplier bahan baku Metal Porcelin dalam proses pengirimannya dan telah dijadikan sebagai prosedur untuk penerimaan bahan baku Metal Porcelin di CV. Brother Dent. Tahapan dalam metode Analytical Hierarchy Process (AHP).

Adapun langkah - langkah dalam metode AHP yaitu :

1. Menentukan bobot kriteria yang dianggap berpengaruh

Tabel 2. Hasil Perhitungan Faktor Penilaian Kriteria

\begin{tabular}{|c|c|c|c|c|c|}
\hline & Kualitas & Harga & Pengiriman & Pelayanan & Fleksibilitas \\
\hline Kualitas & 1 & 3,6 & 1 & 4,6 & 2,6 \\
\hline Harga & 0,3 & 1 & 0,3 & 2,0 & 0,5 \\
\hline Pengiriman & 1,8 & 3,4 & 1 & 4,6 & 4 \\
\hline Pelayanan & 0,2 & 0,7 & 0,2 & 1 & 0,4 \\
\hline Fleksibilitas & 0,4 & 2,6 & 0,3 & 2,8 & 1 \\
\hline Jumlah & 3,8 & 11 & 2,5 & 15 & 8,4 \\
\hline
\end{tabular}

Tabel 3. Perhitungan Matriks Faktor Penilaian Kriteria

\begin{tabular}{|c|c|c|c|c|c|c|}
\hline & Kualitas & Harga & Pengiriman & Pelayanan & Fleksibilitas & Bobot \\
\hline Kualitas & 0,27 & 0,32 & 0,29 & 0,31 & 0,31 & 0,30 \\
\hline Harga & 0,09 & 0,09 & 0,12 & 0,13 & 0,05 & 0,10 \\
\hline Pengiriman & 0,48 & 0,30 & 0,39 & 0,31 & 0,47 & 0,39 \\
\hline Pelayanan & 0,06 & 0,06 & 0,09 & 0,07 & 0,05 & 0,06 \\
\hline Fleksibilitas & 0,11 & 0,23 & 0,11 & 0,19 & 0,12 & 0,15 \\
\hline Jumlah & \multicolumn{7}{|l}{} & 1,00 \\
\hline
\end{tabular}

\section{Menghitung nilai Inkonsistensi}

Setelah menentukan nilai Perhitungan Matriks Faktor seperti pada Tabel 3, maka dapat dilakukan pengujian Inkonsistensi serta penentuan bobot tiap kriterianya. Perhitungan mencari nilai bobot setiap kriteria adalah :

- Bobot Untuk Kriteria Kualitas $=\frac{0,27+0,32+0,29+0,31+0,31}{5}=0,30$

- $\lambda_{\text {maksimum }}=(3,8 \times 0,30)+(11 \times 0,10)+(2,5 \times 0,39)+(15 \times 0,06)+(8,4 \times 0,15)=5,434$ (Consistency Index)

- Consistency Index $(\mathrm{CI})=\lambda_{\text {maksimum }}-n / n-1=(5,434-5) /(5-1)=0,109$

- Consistency Ratio (CR) $C I / C R=0,109 / 1,12=0,097$

Karena nilai CR kurang dari 0,1 maka penilaian Responden terhadap perbandingan berpasangan antar kriteria dapat dikatakan konsisten [9]. 
Jurnal Teknologi dan Manajemen Industri, Vol. 3 No. 2, Agustus 2017

Pascasarjana Institut Teknologi Nasional Malang

\section{Menentukan bobot Sub Kriteria Pengiriman}

Tabel 4. Hasil Perhitungan Faktor Penilaian Kriteria

\begin{tabular}{|c|c|c|c|}
\hline & $\begin{array}{c}\text { Ketepatan Waktu } \\
\text { Pengiriman Sesuai } \\
\text { Yang Telah } \\
\text { Disepakati }\end{array}$ & $\begin{array}{c}\text { Kesesuaian Jumlah } \\
\text { Bahan Baku Yang } \\
\text { Dikirim Dengan Yang } \\
\text { Dipesan }\end{array}$ & $\begin{array}{c}\text { Kemampuan Dalam Hal } \\
\text { Penanganan Sistem } \\
\text { Transportasi }\end{array}$ \\
\hline $\begin{array}{c}\text { Ketepatan Waktu Pengiriman Sesuai Yang } \\
\text { Telah Disepakati }\end{array}$ & 1 & 3,2 & 3 \\
\hline $\begin{array}{c}\text { Kesesuaian Jumlah Bahan Baku Yang } \\
\text { Dikirim Dengan Yang Dipesan }\end{array}$ & 0,3 & 1 & 0,9 \\
\hline $\begin{array}{c}\text { Kemampuan Dalam Hal Penanganan } \\
\text { Sistem Transportasi }\end{array}$ & 0,4 & 1,2 & 1 \\
\hline Jumlah & 1,7 & 5 & 4,7 \\
\hline
\end{tabular}

Tabel 3. Perhitungan Matriks Faktor Penilaian Kriteria

\begin{tabular}{|c|c|c|c|c|}
\hline & $\begin{array}{c}\text { Ketepatan Waktu } \\
\text { Pengiriman } \\
\text { Sesuai Yang } \\
\text { Telah Disepakati }\end{array}$ & $\begin{array}{c}\text { Kesesuaian Jumlah } \\
\text { Bahan Baku Yang } \\
\text { Dikirim Dengan } \\
\text { Yang Dipesan }\end{array}$ & $\begin{array}{c}\text { Kemampuan } \\
\text { Dalam Hal } \\
\text { Penanganan Sistem } \\
\text { Transportasi }\end{array}$ & Bobot \\
\hline $\begin{array}{c}\text { Ketepatan Waktu Pengiriman Sesuai } \\
\text { Yang Telah Disepakati }\end{array}$ & 0,58 & 0,59 & 0,59 & 0,59 \\
\hline $\begin{array}{c}\text { Kesesuaian Jumlah Bahan Baku Yang } \\
\text { Dikirim Dengan Yang Dipesan }\end{array}$ & 0,19 & 0,19 & 0,20 & 0,19 \\
\hline $\begin{array}{c}\text { Kemampuan Dalam Hal Penanganan } \\
\text { Sistem Transportasi }\end{array}$ & 0,23 & 0,22 & 0,21 & 0,22 \\
\hline Jumlah & & & 1,00 \\
\hline
\end{tabular}

\section{Menghitung nilai Inkonsistensi Sub Kriteria Pengiriman}

Setelah menentukan nilai Perhitungan Matriks Faktor seperti pada Tabel 4, maka dapat dilakukan pengujian Inkonsistensi serta penentuan bobot tiap Sub kriteria Pengiriman. Perhitungan mencari nilai bobot setiap Sub kriteria Pengiriman adalah :

- Bobot Untuk Ketepatan Waktu Pengiriman Yang telah disepakati $=\frac{0,58+0,59+0,59}{3}=0,59$

- $\lambda_{\text {maksimum }}=(1,7 \times 0,59)+(5 \times 0,19)+(4,7 \times 0,22)=3,086($ Consistency Index $)$

- Consistency Index $(\mathrm{CI})=\lambda_{\text {maksimum }}-n / n-1=(3,086-3) /(3-1)=0,043$

- Consistency Ratio (CR) $C I / C R=0,043 / 0,58=0,074$

Karena nilai CR kurang dari 0,1 maka penilaian Responden terhadap perbandingan berpasangan antar kriteria dapat dikatakan konsisten.

Untuk penyelesaian hasil sub-sub kriteria dan urutan yang paling penting selanjutnya bisa dilihat pada gambar 1 dibawah ini : 
GOAL

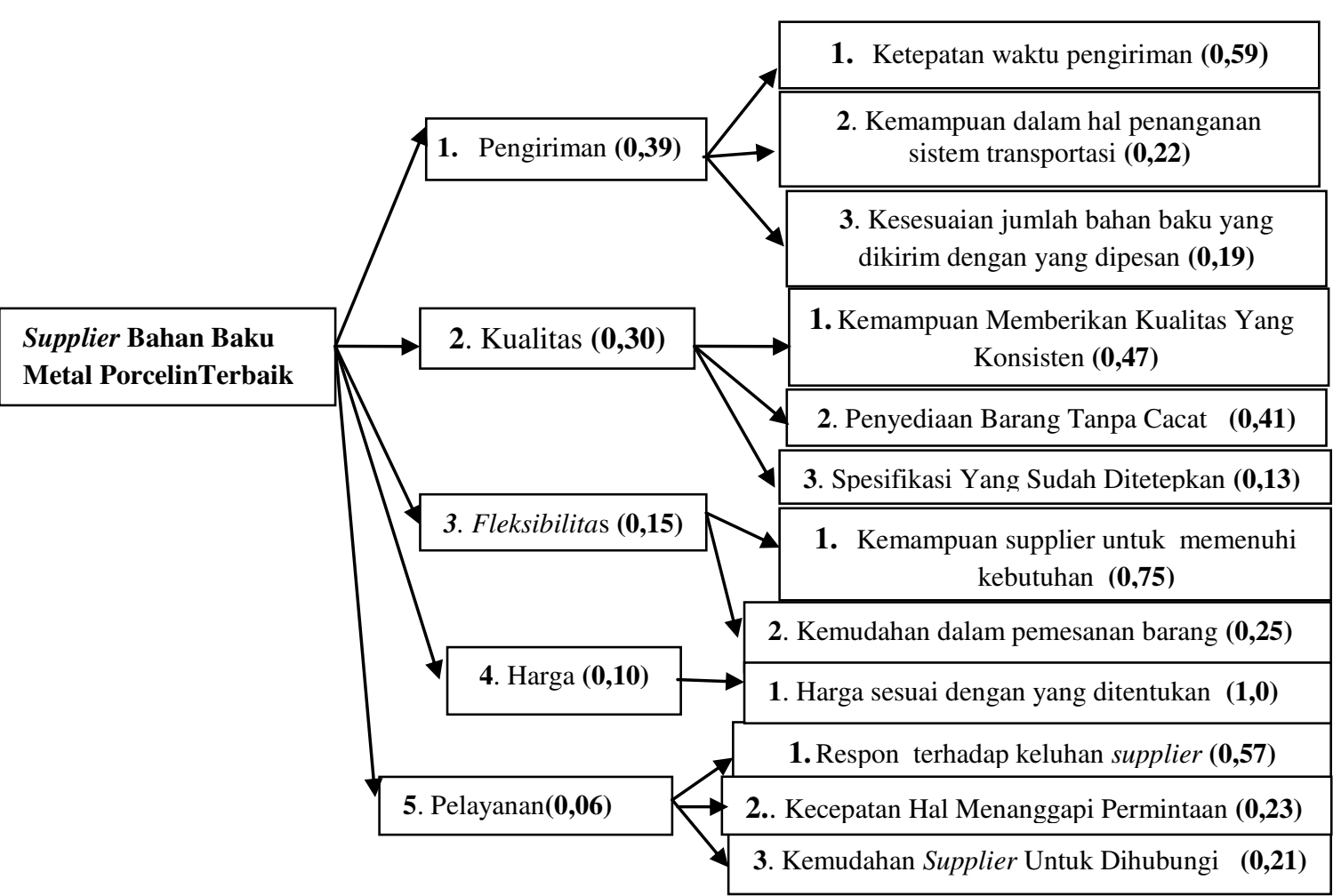

Gambar 1. Hasil Penyelesaian Tahap I dan II Kriteria Dan Sub Kriteria

\section{Memilih Supplier Terbaik Dengan Aplikasi Expert Choice}

Dimana pemilihan supplier terbaik dilakukan dengan cara wawancara terhadap bagian pemesanan barang di CV. Brother Dent dengan memberikan penilaian supplier dengan nilai interval penilaian (1-10) lalu di olah dengan menggunakan aplikasi expert choice bisa dilihat pada gambar 2 hasil pengolahan expert choice.

Tabel 4. Pemilihan Supplier Bahan Baku Metal Porcelin Terbaik

\begin{tabular}{|c|c|c|c|c|}
\hline Kriteria & Sub Kriteria & $\begin{array}{c}\text { Royal } \\
\text { Dent }\end{array}$ & $\begin{array}{c}\text { Tatia } \\
\text { Dental }\end{array}$ & Densplay \\
\hline \multirow{3}{*}{ Pengiriman } & Ketepatan waktu pengiriman sesuai Yang Telah Disepakati & 9 & 8 & 7 \\
\hline & Kesesuaian jumlah bahan baku yang dikirim dengan yang dipesan & 9 & 10 & 9 \\
\hline & Kemampuan dalam hal penanganan sistem transportasi & 9 & 9 & 6 \\
\hline \multirow{3}{*}{ Kualitas } & Penyediaan Barang Tanpa Cacat & 10 & 9 & 7 \\
\hline & Kesesuaian Barang Dengan Spesifikasi Yang Sudah Ditetepkan & 9 & 7 & 6 \\
\hline & Kemampuan Memberikan Kualitas Yang Konsisten & 9 & 7 & 8 \\
\hline \multirow{2}{*}{ Fleksibilitas } & $\begin{array}{l}\text { Kemampuan supplier untuk dapat memenuhi kebutuhan } \\
\text { pemesanan }\end{array}$ & 8 & 10 & 9 \\
\hline & Kemudahan dalam pemesanan barang & 10 & 7 & 8 \\
\hline
\end{tabular}


Jurnal Teknologi dan Manajemen Industri, Vol. 3 No. 2, Agustus 2017

Pascasarjana Institut Teknologi Nasional Malang

\begin{tabular}{|c|l|c|c|c|}
\hline \multirow{2}{*}{ Harga } & Harga sesuai dengan yang telah ditentukan. & 7 & 8 & 8 \\
\hline \multirow{3}{*}{ Pelayanan } & Respon dalam menerima keluhan terhadap supplier & 7 & 9 & 8 \\
\cline { 2 - 6 } & Kemudahan Supplier Untuk Dihubungi & 7 & 10 & 9 \\
\cline { 2 - 6 } & Kecepatan Dalam Hal Menanggapi Permintaan & 9 & 9 & 7 \\
\hline
\end{tabular}

\section{실}

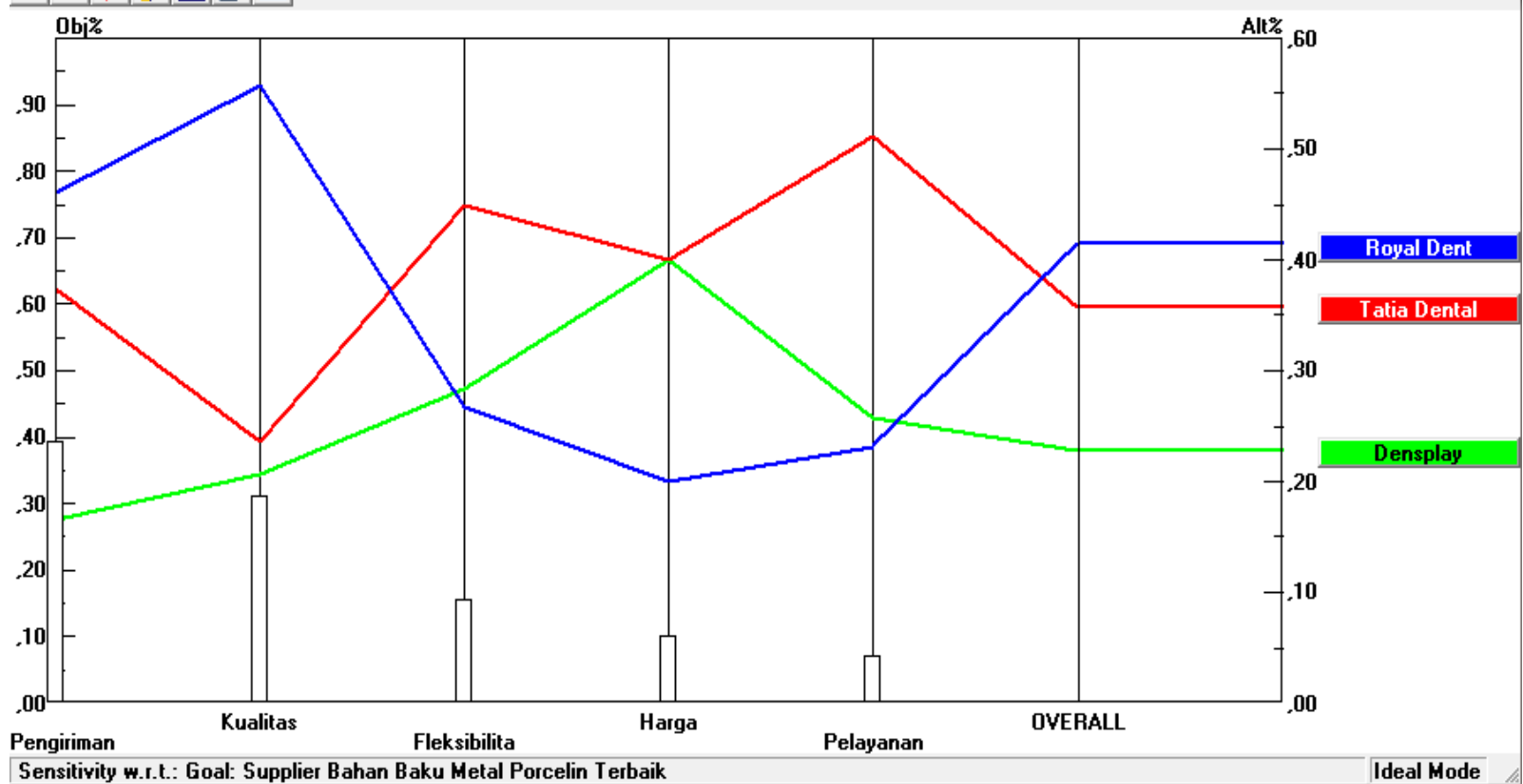

Gambar 2. Grafik Hasil Pemilihan Supplier Terbaik

Pada Gambar 2 dapat dilihat supplier Royal Dent berada di urutan teratas yang berarti supplier Royal Dent merupakan supplier terbaik dilanjutkan supplier Tatia dental dan Densplay di urutan ketiga. Berikut adalah hasil pembobotan nilai supplier pada Gambar 3.

$$
\begin{gathered}
\text { Synthesis with respect to: } \\
\text { Goal: Supplier Bahan Baku Metal Porcelin Terbaik } \\
\text { Overall Inconsistency }=, 05
\end{gathered}
$$

Royal Dent . 414

Tatia Dental $\quad 358$

Densplay $\quad 228$

Gambar 3. Hasil Pemilihan Supplier Terbaik

Dapat dilihat pada Gambar 3 diatas terlihat dari hasil pengolahan data kinerja supplier dengan prioritas dan pembobotan nilai didapatkan nilai tertinggi ada pada supplier Royal Dent dengan nilai 0,414, supplier Tatia Dental diurutan kedua mendapat nilai 0,358, supplier Densplay mendapat nilai 0,228. Dari nilai tersebut supplier Royal Dent merupakan supplier terbaik yang harus dipilih oleh perusahaan karena supplier Royal Dent dapat menjaga konsistensinya dalam menyuplai bahan baku di CV. Brother Dent [10].

\section{Kesimpulan}

Hasil kuesioner 1 menunjukkan bahwa kriteria yang baik dalam memilih supplier bahan baku metal porcelin adalah Kualitas, Harga, Pengiriman, Pelayanan, Fleksibilitas. Pengolahan data pada Kuesioner 2 menggunakan metode AHP diketahui kriteria pengiriman menjadi prioritas utama yaitu dengan bobot 
0,39 berikutnya diikuti dengan kualitas dengan bobot 0,30 , Fleksibilitas dengan bobot 0,15 , harga dengan bobot 0,10 dan pelayanan dengan bobot 0,06 . Hasil penilaian dari hasil wawancara untuk menentukan supplier terbaik yang sudah diolah menggunakan aplikasi Expert Choice menunjukkan supplier Royal Dent sebagai prioritas pertama dengan bobot 0,414 dilanjutkan Tatia Dental dengan bobot 0,358 dan densplay dengan bobot 0,228 .

\section{Daftar Referensi}

[1] Pujawan, N.I, Supply Chain Management. Surabaya: Guna Widya, 2005.

[2] Mulki dan Raihan, Aplikasi Analytic Hierarchy Process dalam Pemilihan Supplier pada Supply Chain Mangement. Jurnal Teknologi Industri, 2005, No 2.

[3] Eri Wirdianto, Epira Unbersa, dalam Penelitiannya Aplikasi Metode (AHP) Analytical Hierarchy Process dalam menentukan Kriteria Penilaian supplier, No. 29, Vol. 2, Thn. XV, April 2008.

[4] Eko Darmanto, Noor Latifa, Nanik Susanti, Penerapan Metode AHP (Analytic Hierarcy Process) untuk menentukan kualitas Gula Tebu, Jurnal SIMETRIS, Vol. 5, No. 1, April 2014.

[5] Kusrini, Konsep Dan Aplikasi Sistem Pendukung Keputusan, Yogyakarta : Penerbit Andi, 2007.

[6] Surjasa, Dadang, Pudji Astuti, dan Hario Nugroho, Usulan Supplier Selection Dengan Analytical Hierarchy Process Dan Penerapan Sistem Informasi Dengan konsep Vendor Managed Inventory Pada PT ABC, 2006.

[7] Yanuar Angga Prayoga, Sistem Pendukung Keputusan Pemilihan Supplier Botol Gallon Menggunakan Metode Analytical Hierarchy Process (AHP), 2016.

[8] Sambas Sundana, Yossy Yulia Sari. Analisis Pemilihan Supplier Pada Komponen Lamp Cord Assy Untuk Speedometer Honda Blade Di PT. Indonesia Nippon Seiki.

[9] Saaty, Thomas L, Fundamentals of Decision Making and Priority Theory with the Analytic Hierarchy Process. RWS Publications : Pittsburgh USA, 1994.

[10] Gabriela Ryane Pangemanan, Celcius Talumingan, Benu Olfie L.S, Ellen Tangkere. Model Pemilihan Pemasok Bahan Baku Kelapa Pada PT. Royal Coconut Di Minahasa Utara Dengan Pendekatan AHP (Analytic Hierarcy Process. 